\title{
Sustainability and the Politics of Transformations from control to care in moving beyond Modernity
}

For Meadowcroft et al, (ed) What Next for Sustainable Development?: Our Common Future at Thirty. Andy Stirling, SPRU and the STEPS Centre, University of Sussex, May 2018

\section{Sustainability: from controlling progress to caring transformation}

Of the many dimensions of Sustainability, perhaps none are at the same time so ambivalently intimate and antagonistic, as its relations with Modernity. Despite a diversity of views on what constitutes either Modernity or Sustainability, it is striking that themes coming most repeatedly to the fore in characterising Modernity, tend also to be prominent in defining Sustainability.

For instance take the theme of control. This is an essential strand in defining the distinctive patterns of practice in Modernity, with contrastingly-diagnosed modalities of control variously including: rationalization, industrialization, bureaucratization, individualization, democratization, as well as nation-forming, capitalization and disenchantment from tradition (Stirling, forthcoming). All are analysed to involve some kind of effort at control. Correspondingly, control is also central to modernist understandings of the world, in efforts to: reduce complexity; standardise diversity; aggregate variabilities; integrate plurality; externalise uncertainty - and so discipline change. Equally in its materialities and its imaginaries, then, Modernity is centrally about aspirations to control.

Whatever view is taken, one of the most obvious corollaries of all such modernist efforts at control, is that - for all their spectacular successes (and even in their own terms) - they often go awry. In the course of their development both before and after the Brundtland Commission, then, Sustainability movements can be understood in this light (Redclift 1987)(Doherty \& Geus 1996). For Sustainability is arguably the single most important general international critical response to the manifest failures to which modernist romanticisations of control can lead. In terms of definitions that will be discussed in a moment, Sustainability presents a stark contrast with the controlling ambitions of Modernity, in being concerned with many ways of caring for the neglected unintended consequences, for: people, societies, ecologies and the future of the world (Bellacasa 2017)(Robinson 2011). Indeed, it is as this political reaction to failures of modernist control, that Sustainability is critiqued by detractors, as being about 'holding back' modernistic ideas of progress (Lovelock 2006).

Yet there is also a sense in which these caring sensibilities of Sustainability may actually be seen as a kind of intensification in imaginations related to control. In its modernist forms, control involves 
deliberate interventions in the world in order to pursue the tantalysingly under-specified quality of 'progress'. Since social progress can only be documented in relation to some normative frame of intended ends, this raises common ground. For Sustainability is also about pursuing collectively desired ends - albeit in this case more explicitly defined to concern various permutations and inflections around canonical Brundtland values of human wellbeing, social equity and ecological integrity. In these terms, Sustainability is about sustaining into the future, continuous improvements in these particular qualities (Stirling 2014a). Yet if efforts to progress towards any kinds of end are to count as 'control', then the aims in question must be realised in very specific, predictable fashions, without unintended collateral effects. Otherwise, what is occurring is not a process of control, but merely the exertion of impacts.

That control is not the same as impact, may seem obvious. But we will see later there is surprising high-level scientific confusion on this point. For now, it is simply enough to note that impacts are often undermining of intended ends. So it is in this specific sense of enhancing progressive agency in social action, that the caring disposition of Sustainability might be seen to resonate with Modernity albeit in ways that hold profoundly transformative implications. What Sustainability requires in the above terms, then, is more inclusive deliberation in pursuit of collective social ends, whilst radically reducing unwanted impacts on people and the Earth (Redclift \& Springett 2015)(Atkinson et al. 2014)(Leach et al. 2010). Sustainability thus aims to make social agency more effective and its consequences more in accord with shared aims. It is about exercising collective intentions not merely with respect to the pace of 'progress' in any given context, but also over its normative direction (Stirling 2006).

But the crucial point here, is that once the underlying qualities of action are deepened and opened up in this way, the issue ceases to be strictly one of control (Plumwood 1993). This is why a better description for what Sustainability is striving for in these aspired enhancements of social agency, are best characterised not as control, but (drawing, for instance, on feminist theory) as 'matters of care' (Bellacasa 2017)(Fisher \& Tronto 1991). In seeking to understand the crucial detail of this distinction, an analogy drawing on society's relationships with children might be illuminating (Gilligan 1993)(Held 2005). And the modernist notion of "progress" can also remain broadly meaningful here. After all, societies care very much about the ways in which children develop, but (however it may manifest in some settings), this is not typically best describable as an ambition to control.

Key in the example of child-rearing (as in Sustainability), is that care is typically greatly more flexible, open and plural than is captured by the idea of control (Gilligan 1993)(Held 2005). Ends and intentions at issue are generally more diverse and carefully deliberated between subjects and objects of care. The means are more mutualistic than deterministic. There is a more relational than 
categorical stance, with greater humility and reflexivity over complexities, uncertainties, and other (third) loci of agency. Deeper precaution is adopted towards adverse effects, than is captured in controlling notions of 'trade-offs'. It is these kinds of differences that lead efforts to exert general controlling relationships over children to be widely regarded (across different societies) as a pathology. So, it is distinctions like these that make both relations with children (like the concerns of Sustainability) better envisaged to be more about 'care' than 'control'.

Since before the Brundtland Report, Sustainability movements have contested in all these ways, the multiple failures of modernist control. They express instead, how intensely people care (in different ways) for each other and for the future of the Earth. This is why mutualistic languages of care are more prominent in discourses on social justice and environmental protection than deterministic terminologies of control. Indeed, rhetorics of regulatory control - of 'safe levels', 'critical loads', 'dilute and disperse' or 'risk based containment' - are more often defensive reactions against Sustainability concerns. And this is why discussions of the Brundtland triad of values are for their part, so pervaded by reference to care (Norton 2003)(Pope_Francis 2015).

Of course, the people, societies and ecologies for which Sustainability cares, display their own forms of agency, making them not only inappropriate but recalcitrant as objects of attempted control. And the above features of care as distinct from control, also chime with the resolutely plural nature of the Sustainable Development Goals (SDGs) - attending to ends not just means and to many details, dimensions and interpretations typically neglected by control. They define a political space for global societies to deliberate together, to uphold diverse otherwise-marginalised agencies, in order to care for sustained, worldwide transformations towards greater wellbeing, equality and ecological integrity (UN 2015).

At face value, however, this kind of care might still seem broadly congruent with professed aims (and frequent claims) made on behalf of Modernity, concerned with improving the lives of people and the societies and environments in which they live. After all, if such improvements are not 'progress', then what is? And it is certainly true that control and care should not be overly starkly separated. Often entailing each other, they are as inter-related conceptually as they are entangled in practice. For instance, intended expressions of care may be enacted in a ways that can be perceived as controlling (Benner 2000). Either way, each can be normatively positive under particular views in different contexts. But a distinction doesn't have to be either a dichotomy or exclusive, in order to be illuminating - nor to hold salient lessons for action.

So, it implies no denial that modern science, technology and institutions have brought benefits, to note that these arise where (and for whom) they do, more as collateral outcomes of preoccupations 
with contingent controlling means, than with carefully deliberated wider social ends. In prevailing modernist views of progress around the world, the focus is more on incumbent sectoral instruments for notionally controlling some presumptively self-evident development path, than on deliberating its desirable orientation.

And as Modernity ironically becomes an entrenched tradition in its own right, associated discourses, institutions and practices focus ever more intently on the particular privileged means to perform ideas of 'advance', rather than on rigour or accountably in shaping their ostensibly associated ends. So 'advanced science', 'high technology', 'free markets', 'commercial productivity', 'economic wealth', 'national interest', 'pro-innovation policies', 'monetised values', 'intensive production', 'integrated knowledge', 'global solutions', 'future visions', 'international institutions' and 'planetary management' all tend to be treated as sufficient as ends in and of themselves. This is why Sustainability is so important, as the only comprehensive codified internationally-agreed general normative framework for orienting the directions (rather than just the pace) of social progress. It is this fixation on instruments of control (rather than the normative ends to which they might be hoped to lead), that arguably make Modernity so uncaring. And it is here again that Sustainability movements are also deeply challenging to some of the most powerful interests in Modernity - by caring for (and so explicitly interrogating) underlying ends, as well as favoured means. What Sustainability initiatives like the SDGs are distinctively caring for, are effective ways to focus directly on contrasting implications of alternative (especially marginalised) driving interests and hopes. By making these processes explicit and inclusive, critical engagements are enabled with many powerfully-favoured infrastructures, practices and institutions that can be very uncomfortable for entrenched incumbent interests in different sectors.

This is the political niche that initiatives like the SDGs distinctively fill. Forensically negotiated and ratified by almost all the world's nations, they are full of ambiguities, compromises and 'civilising hypocrisies'. But for all this, the SDGs provide a uniquely clear normative framework and process for debating which values, interests and possibilities are most cared about in the collective shaping of social, technological and associated environmental change. Here, two more detailed challenges for Modernity loom especially large. First, there is the much-criticised plurality of what the Economist disparages as the "Stupid Development Goals" (Economist 2015). Although emphasizing a clear general orientation, the 17 goals and 169 targets (and even more metrics) define a broad evaluative arena, not a singular technical criterion. This prevents 'progress' being reduced to hegemonic assertions of some singular 'public interest' or to whatever developments happen to be emerging anyhow. So this enabling of more questioning politics can be deeply threatening to incumbency. 
The second striking challenge of the SDGs is that (for all the diversity of this array of legitimate ends), they entirely exclude many of the most formatively motivating enthusiasms of Modernity. In other words, the values and interests that most strongly drive the fixated instruments of Modernity, are actually in deep tension with Sustainability: private profit; corporate power; military might and national standing. This is not a novel point. But it is remarkable to see the SDGs document this uncomfortable political reality in such a graphic and high profile way. Whatever progress might be, it is emphatically not measurable by the dominant evaluative frames institutionalised in contemporary Modernity. This is why it is so clear amidst the complexities and ambiguities of the SDGs, that so many entrenched current directions of change in the world can confidently be diagnosed to be so manifestly unsustainable (Barry 2012).

What Sustainability is arguably helping to do, then, is move global imaginations of social progress away from unaccountable and unsustainable modernist imaginaries of control and towards more explicitly-deliberated commitments to care - for human wellbeing, social equity and ecological integrity. But what instruments like the SDGs amount to here are also only means rather than ends. The real progressive significance of current Sustainability institutions, practices and discourses is that they offer high-level spaces, provocations, pivots and ratchets enabling political traction for grassroots struggles over specific directions for change in particular settings. Again, this is more about care than control. Acknowledging uncertainties, complexities and unintended effects in context-dependent outcomes, Sustainability discourse is a resource to enable plural, ambiguous and messy political agencies - for marginalised interests that history shows must always struggle to make (rather than be given) progressive transformations.

\section{Control Backlash I: cargo cult subversions of Sustainability}

This contrast in controlling and caring approaches to interlinked progressive social, technological and environmental change is not just a matter of discourse in high level governance. There are some very immediate implications for the concrete structures and procedures that steer the global political economy, like: world trade rules, product standards, environmental instruments, ethics regulations and mission oriented agencies. In keeping with a controlling (more than a caring) disposition, these tend strongly to focus not on assessing alternative pathways for progress, but on establishing acceptance just for the single most powerfully-supported trajectories. Attention is directed at the 'safety', 'tolerability', 'acceptability' or overt 'promotion' of this focal trajectory. It is rare to find consideration extending in a balanced way across a range of alternative means to the same ends. 
Entirely absent, is any serious deliberation over wider understandings, values and interests that constitute different possible ends.

So, what is typically asked in current regulatory activity worldwide across different sectors, is merely "how fast?"; "what risk?"; "who leads?" - rather than "which way?"; "who says?" or "why?". Here again we find the blinkered attention of modernist control: modulating the implementation of some presumptively inevitable single trajectory (as a means), with the underlying driving ends remaining unacknowledged, unaccountable and undiscussed. And effects of this hegemonically closed style of control are very politically tangible in decision making across different sectors: the main trajectories for change tend disproportionately to be those that favour the most powerful proximate interests.

Although details might be contested, this general picture of overbearing domination by incumbent interests is visible everywhere. In the health sector, for instance, it is well documented how private profits for pharmaceutical companies tend to be emphasised over the most pressing global health priorities. In agriculture, the preferred seed production techniques (like transgenics) are those which offer more benefits to producers than to farmers or consumers (for instance in creating dependencies on other proprietary products like pesticides). 'Consumer markets' lock in to industrial products that maximise rents on existing value chains and supply networks, rather than encouraging less tangible services involving new forms of social organisation. In areas like water, energy, transport and communications provision, developments are prioritised that maximise 'load factors' of existing infrastructures. With national policies taxing employment more than capital or environmental harm, automation and pollution are favoured over people or ecosystems. And across the board, it is IP-intensive science and technology that are privileged over social innovations or open source responses that often offer far better outcomes for the most disadvantaged people (Science 2014).

So, under persistently controlling modernist imaginations, institutions and practices, a kind of Panglossian fatalism descends - celebrating as 'progress' in any area whatever happens to unfold there under prevailing structures of power and privilege in science, technology and wider politics. Innovation is so strongly identified only with the most dominant trajectories, that policy dilemmas are reduced merely to striving to "forge ahead" with the "first movers" or against being left behind as a "latecomer" in some presumpitively inevitable development pathway (as a means), whose wider driving social ends remain seriously under-discussed. Accordingly, 'development' itself is treated merely as a process of "catching up", in settings that are otherwise stigmatised as "lagging behind". This can lead everyday policy rhetorics in supposedly 'democratic' countries to take on a sometimes shockingly totalitarian hue in their denial of choice. Favoured trajectories are lauded as 
comprehensively "pro-innovation", with scepticism stigmatised as if generally "anti-science". This is like trying to reject specific criticism of a particular policy by branding it generally 'anti-policy'. It is a sign of the depth of the controlling blinkers of Modernity around science and technology, that this language is so routine. So, by these kinds of mechanism, progressive ambitions are restricted by regulatory protocols merely to focus on "tolerable risks" that can be achieved by "environmental mitigation" of whatever is the favoured trajectory. Progressive policies are constrained just to "trickle down" from this one path. With all such conventions constricting imaginations to just one "way forward", the richness of human social possibilities for progress reduces to a single-tracked "race". Ubiquitous "roadmapping" exercises oddly highlight only this same single privileged road. That noone needs a road map, when there's only one road, completes the hegemonic closure. It is in these terms, that some Sustainability interventions are arguably most effective. More explicitly caring forms of governance like particular SDGs, Agenda 21 or the precautionary principle display a number of qualities that distinguish them from this overbearing modernistic discourse of control. They enable deeper scrutiny of contending ends as well as alternative means. They are broader in their attention to plural agency, multiple issues, divergent settings - and to alternative possibilities, uncertainties and societal perspectives. They are more open in their abilities to nurture diverse repertoires of institutions and practices (rather than single technology-based trajectories). All this can help counter adverse effects of incumbent interests in different sectors and so help enable a host of more Sustainable pathways for change, that currently controlling visions tend to neglect. But this challenge is not uncountered. Just as Sustainability begins effectively to contest this central syndrome of Modernity, so it is perhaps not coincidental that a series of new political developments begin to sow confusion and re-assert control. Even in some heartlands of debate over social justice and environmental protection, newly-emerging "techno-optimist", "eco-modernist" and "green growth" visions of Sustainability obscure and diffuse the challenge to Modernity. These serve to intensify controlling tendencies - assertively taking for granted what directions count in research, innovation or growth and focusing excitedly instead on narrow imperatives for "acceleration". With technologies seen as inexorably "converging" towards a notionally inevitable "singularity", the locus of control moves even further towards to an imagined autonomy in technique itself (Ellul 1989). Remarkable instrumental advances in areas like robotics, nanotechnology, synthetic biology, neuroscience, machine intelligence and global modelling shift the imagined site of agency even further from accessible human politics. Compounding the elision of ends and means and the conflation of impacts and intentions, the fallacies and paradoxes of control are further exaggerated. 
Nor does this backlash against Sustainability stop there. Under many "cornucopian", "neophiliac", "technocentric" and "solutionist" views, Sustainability itself is subverted to become more about existing means than prospective ends. Not only is prevailing practice held to be synonymous with 'progress', but Sustainability itself reduces merely to the 'sustaining' of 'business-as-usual'. In this way favoured technologies are advanced not merely as possible options for achieving greater Sustainability (which is often dubious), but as essential. Senior scientific figures claim, for instance, that there is "no alternative" to nuclear power as a response to climate change. Military nuclear reactor designs are rebranded as "green" nuclear power. Obscurely-funded 'repentent environmentalists' loudly proclaim their techno-optimist conversions and brand longstanding Sustainability concerns over technologies like synthetic biology or nuclear power to actually be antiSustainability. And instead of including tried and tested practices of low-input ecological farming, leading academic bodies exclusively promote speculative extensions of existing high-tech trajectories as "sustainable intensification" (Baulcombe et al. 2009). Just as complete elimination of carbon emissions becomes cost-effective in key sectors, "climate geoengineering" grows ever more prominent around the world (Mclaren 2018).

These are all practical examples of the challenges faced by the new politics of care opened up by Sustainability. They illustrate many ways in which the controlling dynamics of Modernity are intensifying in the face of this new politics. Efforts are being made to appropriate Sustainability itself as just another "cargo cult" notion of human progress - as something that just "spins-off" or "trickles down" from pursuit of existing structures of interests in technology, the economy and wider politics. And it is in seeking to defend against these distorting pressures, that the contrast suggested here between the controlling imagination of Modernity and the caring imagination of Sustainability may be of use.

\section{Control Backlash II: nudge, nexus and Anthropocene planetary management}

The backlash against the caring sensibilities of Sustainability is not confined to the single-track, racelike, cargo-cult subversions of development discourse just discussed. Similar re-assertions of control imaginations are arguably underway even closer to the home ground of Sustainability, in high-level governance arenas directly concerned with environmental protection and social justice.

One example lies in the growing body of "eco-catastrophist" science warning fearfully that the world is faced with a "perfect storm" of environmental threats. Even if not as existential as sometimes implied for the planet as a whole, grave implications clearly arise for many livelihoods, societies and ecologies. But in burgeoning discussions of this "nexus" of "grand challenges", it is often revealingly 
ambiguous (and so unaccountable) what 'the nexus' actually involves. And it seems sometimes that the performance of 'grandness' is at least as important as the substantive addressing of 'challenges'. Meanwhile, in all the urgent attention to unfolding emergence, it is often forgotten that longstanding entrenched (very acute and contemporary) forms of vulnerability and injustice, remain the most serious aggravating factors for people who stand to be most affected by clamouring "new" forms of threat. The real urgency arises not in scientific projections, but real-time political responsibilities. Yet with shrill cries that there are "one hundred months to save the planet" (Hulme, 2010), modernist control imperatives treat issues around contemporary social ends as if they were just about prospective instrumental means. So, these elisions translate responsibilites to care for presentlyprevailing injustices and vulnerabilities into expediently-deferred incumbent agendas of control. And here a further striking contrast also arises. It is explicit in Brundtland's vision of Sustainability, that it should be the diverse interests and agency of the most vulnerable and affected people, which should be prioritised in imperatives the report repeatedly identifies for "inclusion", "participation" and "greater levels of democracy" (Brundtland 1987). Yet current controlling moods around the 'nexus' of 'grand challenges' - of impatient urgency, uncompromising fear, expert dependency, technical 'tools' and business pragmatism - also directly erodes these more 'caring' processual commitments of Sustainability (Stirling 2015).

Here again, a willingness to focus only on uncomplicated diagnoses, 'realistic' prescriptions and singular solutions means it is primarily technological responses that come to the fore - especially those building on the most immediately available (ie: incumbent) infrastructures and the most overbearing commercial interests. By contrast with the acknowledged plurality of the SDGs, the asserted notional singularity of 'the Nexus' expediently suppresses the diversity of water, food or energy (or urban, soil, security, climate, or other) systems supposedly addressed and the complexity of their context-specific interactions. In the resulting exaggerations of tractability to marginal adjustments on business as usual, it is again means that are privileged over ends.

These specific re-assertions of control, further align with a wider more generally growing mood of environmental authoritarianism, in which Sustainability challenges are increasingly held to be too pressing to be reliably achieved by any democratic means. Here, the manifest lack of progress registered under the SDGs is attributed not to resistance by entrenched incumbent interests, but to a "failure of democracy" (Shearman et al. 2007)? Instead of being recognised as essential to the core Sustainability value of enabling plural social agency, open forms of democratic discourse are characterised as an obstructive or dispensable "luxury" (Haan \& Sierman 1996). The iconically influential environmentalist, James Lovelock (for instance), suggests that "it may be necessary to put 
democracy on hold for a while" (Hickman 2010). The main European Commission news website queries even whether democracy itself has become an "enemy of nature?" (Euractive 2010).

Similar growing authoritarianism is also evident in the ways many influential institutions in environmental governance are increasingly deprioritizing previous hard-won duties to be transparent, responsive and accountable to citizens and public interests, in favour of more covert strategies for the 'nudging' of 'users' and 'consumers'. Public, private and civil society organizations alike, seem ever more preoccupied with controlling and explaining their prior established ends and means, rather than listening or adapting to criticism. Risk is repeatedly interpreted in terms of reputation. Trust is emphasised overwhelmingly as a virtue of the powerless and an entitlement of the powerful - rather than trustworthiness going the other way.

Perhaps the most momentous example of this backlash by authoritarian control discourse, however, is all the more insidious for being so widely supported by many of the most sincere constituencies around Sustainability. This concerns the plethora of current initiatives to reframe Sustainability in scientific terms of 'the Anthropocene' and 'planetary management'. Here, even geology is dragooned into emphasizing technical themes of control. If adopted as a new geological epoch as currently influentially suggested, the 'Anthropocene' would follow on from a tiny 11,700 year Holocene, itself oddly tacked on to the end of the preceding 1.6 million year Pleistocene. Simply marking the point where Earth moved out of the latest (so far) in a long series of glaciations, the Holocene itself already reflects an anomalous imagination of human exceptionalism and propensity to control.

Other than this being a period when human populations grow and technological activities intensify, there are few clear geological reasons for distinguishing the Holocene as anything more than just one among many interglacials. The sustaining of relative climate stability over such a brief period is not geologically distinctive. The oddity is compounded in that all previous epochs extend to many tens of millions of years. Yet with the Anthropocene, this same human- and techno-centric bias significantly intensifies. So, in just the fashion of other forms of control backlash, Anthropocene planetary management is itself defined in terms of means rather than ends. Reifying - even celebrating - the imagination of control, the ends for human agency are simply assumed and treated as homogenous Of course, to see this is not to downplay human responsibility for the massively devastating global impacts of industrialised societies. Aspects of this destruction will doubtless be geologically visible in the distant future. But it is precisely the point being made in the proposing of the Anthropocene, that this devastation is unsustainable even over the short term - let alone over an entire geological epoch notionally extending to many millions of years. Previous episodes of geological transformation are plentiful, but not taken to be diagnostic of entire subsequent epochs. If the only way Modernity can 
acknowledge its own calamitous impacts is in a scientistic geological frame then - like a large meteorite impact - this is more accurately envisaged not as a geological epoch, but as relatively brief horizon of destruction, of the kind that routinely divides many epochs. Anthropocene imaginings, then, are not of an extended period, but of a tragically brief prospective geological moment. The nature of any ensuing epoch is even more beyond human control than is the present troubled world. One reason diverse Anthropocene ideas are so controlling, is that they deny this reality.

So what difference does it make? Again the answer arguably lies in modernistic incentives to emphasise control. To portray the Anthropocene as a fleeting horizon, would unpalatably understate the hubristic controlling ambitions of Modernity. For it is this sensibility that again repeatedly comes to the fore as a distinguishing feature of ideas about the Anthropocene: the same striking confusion between 'impacts' and 'control' referred to earlier; the same deferred responsibility. The majority of key texts on the Anthropocene refer to this aspiring epoch not just in terms of inadvertent collateral destruction, but in far more ostensibly deliberate senses of indefinitely-extending 'control' or 'domination' (Vitousek et al, 1997; Steffen et al, 2011).

In the seminal paper proposing a new Anthropocene epoch, for instance, the role of humanity is repeatedly referred to not as destroying, but as "taking control of Nature's realm" (Crutzen and Schwägerl, 2011). Nor is such control just prospective, but clearly asserted as if it already existed with claims that a vision of "humans as the masters of planet Earth ... has turned into a stark reality" (Crutzen and Schwägerl, 2011). And this converts very graphically into a key proclaimed aim for the Anthropocene - quite shocking in its implications for a world of hitherto manifestly naturally varying climate - of a technical mission to maintain "optimal Holocene conditions" (Rockstrom, 2009). The climate itself has become an object of control, to suit particular kinds of political economy.

As more widely in Modernity, this Anthropocene confusion of impact and control, is like describing the proverbial bull as 'controlling' its unfortunate china shop. As we have seen, what defines a general relation of 'control' (rather than 'impact'), is that it emphasises determining intent, with presumptions that: agency is singular; relevant ends can be taken for granted; attention focuses just on means; uncertainties can be neglected; all salient variables are fully tractable; and there will be no collateral effects. It is in this mode that the casting of Sustainabiltiy as "planetary management" seeks to "take charge" of nothing less than the "control variables of the Earth" (Rockström et al, 2009). Whether celebrated or decried, this is how technical 'Anthropocene' discourses are reframing Sustainability - not as a challenge for plural societies to be more caring about each other and for the Earth, but for a notionally singular and depoliticised human agency to project even further the controlling imagination of Modernity into hitherto unprecedented global and geological scales. In the historic moment when it is most challenged, the modernist hegemony of control seeks to extend 
itself even further out of political reach - into a new scientistically-justified manifesto for planetary destiny.

That humanity as a whole has never even undertaken - let alone controlled (still less achieved) - any single explicitly and collectively controlled end, makes it almost comically eccentric to expand such manifestly hubristic ambitions (even claims) to prospective planetary epochs of millions of years. And (despite their positive intents) notions of a 'good Anthropocene' compound the wry mood, by taking a category solely defined by accelerating catastrophic impacts and seeking to flip this merely by rhetorical flourish into something somehow supposedly 'good' (Revkin 2014). To the extent that any conceivable Anthropocene might 'good' in the sense of Sustainability values, it would not - according to notions defined either by impacts of control - be an 'Anthropocene'. Whether positive or negative, the relational effects reinforce a powerful, pervasive imagination of control. Even the mere category of 'the Anthropocene' - of any kind and even if inadvertent or intended critically - signifies a desperately-defensive 'control cult' of Modernity.

\section{From Controlling Transitions to Caring Transformations}

So what are the practical implications of this analysis? How to defend hard-fought political gains by Sustainability from currently resurgent modernist hegemony? How to reverse erosions of scope for democratic struggle - as if this were an 'enemy' or a 'luxury' that should be 'put on hold'? How to resist wider authoritarian appropriations of languages, institutions and practices of Sustainability and their subversion to technical agendas of control, rather than more emancipatory politics of care? An answer to these questions might begin by considering where the Sustainability movement came from in the first place - and the nature of the political forces that have most supported it. In keeping with Brundtland's emphasis of themes of participation and democratic struggle (Brundtland, 1987), Sustainability discourse was historically pressured onto high level international agendas (like the World Commission on Environment and Development) through emergent waves of collective action and "uninvited" public engagements in pursuit of social justice and environmental protection. Just as in other earlier movements for the emancipation of subjugated classes, ethnicities, slaves, workers, colonies, women, young and disabled people and diverse sexualities - Sustainability was only pressured to become a focus for bodies like the Brundltand Commission, through diverse, protracted, radically-challenging and overtly-political agonistic struggles by subaltern social movements (Mouffe 1999).

Mediated often in new musical and artistic forms, these movements acted through the deepest and broadest political spaces of culture as a whole. These unruly processes were a far cry from the kinds 
of expert-led 'integrated assessment' or 'evidence-based' control highlighted in contemporary elite planetary management. Far removed from the 'cockpitism' of transitions processes like that so unsuccessfully presided over by the IPCC, transformations of this kind are more about a mutuallychoreographed rhizomic 'culturings' of change. Here knowledge and action are not forced into vertical separation by elite institutional etiquettes and divisions of labour, but are freely combined, with new configurations of practice, identity, values and interests horizontally shaping each other. In keeping with the aphorism that 'the medium is the message', these ways in which Sustainability movements came into being and have thrived so long, also strongly resonate with their normative content (Stirling 2016). Again, this key strand of Sustainability arose historically more through a messy mutualistic politics of care, than by orderly hierarchical instruments of control. Take, for instance the development of issues around occupational hazards, resource degradation, consumer chemicals, ionising radiation, atmospheric pollution, water contamination and climate change (Gee et al, 2001; EEA, 2013). All were typically pioneered by subaltern communities of workers or affected people, then picked up by the social movements who cared for these interests. In each case, it was caring recognition of uncertainties that advanced progressive causes, not the controlling assertions of 'uncompromising', 'non-negotiable' certainties now redolent of controlling Anthropocene discourse.

Indeed, these imperatives were at each stage strongly contested by precisely the authoritarian controlling language of risk, now used by mainstream science and high-level governance institutions seeking to champion the reframing of Sustainability as 'planetary management'. The kinds of controlstyle aggregating analysis, optimising models and categorical boundaries that now structure ' $\mathrm{global}$ assessments', for 'earth systems governance', were - like earlier notions of 'assimilative capacities' all used in efforts to resist Sustainability movements. The formative kinds of concrete action that most grew momentum around Sustainability issues, were less about quantitative expert control of risks, and more about qualitative values of care for fellow people and their environments.

Turning from the motivating problems to the aspiring solutions, similar general patterns can be seen. Innovations such as wind turbines, ecological farming, super-efficient buildings, and green chemistry all owed their pioneering origins and early development to subaltern social movements (Smith et al. 2013; Garud \& Karnøe 2003). All were systematically marginalized (if not actively supressed), by incumbent interests in science, government and industry. And again, these transformative responses were nurtured not by controlling management, but by mutualistic - caring - struggle. That so many of these innovations have now become central elements in prospective transformations to Sustainability, is despite - rather than because of - 'sound scientific', 'evidence based' elite policy 
discourse. Again, it was the politics of care, that brought these presently-growing signs for hope into being, far more than the currently-celebrated technical imaginations of control.

So at the end, we come to the question of how best to continue the struggles of - and towards Sustainability: to rebalance modernist technical fixations with control, by culturing a newly vibrant mutualistic politics of care. And here for the purpose of drawing practical conclusions, it might be useful to think as a heuristic, about two ideal-typical imaginations of radical social change that pervade current global policy debates around the implications of Sustainability (Stirling 2011).

On one hand, are what might called 'sustainable transitions': directed under incumbent structures by means of orderly management according to tightly-disciplined technical expertise and technologybased innovations. Often driven especially by fear, these focus largely on presumptively well-known and singular means, with details of the wider driving ends remaining relatively less questioned. Notionally rigid categories are emphasised over inconveniently open relations. This style of change typically emphasizes integrated multidisciplinary science directed at instrumental management through formal procedures in hierarchical organizations sponsored by the convening power of government. Exemplified in a range of currently widely-propounded frameworks, this is the mode of change most characteristic of modernist hegemonies of control.

On the other hand, there are 'transformations to Sustainability': involving more diverse, emergent and unruly political alignments. Best driven more by hope than by fear, these reflect less disciplined (incommensurable, tacit and embodied) knowledges and social (more than technical) innovation. They involve pursuit of contending (sometimes even presently unknown) means towards contrasting ends that remain hotly contested. The focus is on open-ended relations rather than supposedly fixed categories. So, in this more political mode, space opens up for subaltern interests, social movements and civil society to struggle for in ambiguous (sometimes invisible) ways to orient the broader normative and cultural climates in which all explicit structures are set. Challenging incumbent interests associated with the modernistic hegemony of control, this idea is more congruent with the mutualistic pluralism of caring imaginations of Sustainability.

The point here is not to insist on terminology. The words 'transition' and 'transformation' are often entirely-reasonably used in interchangeable ways. Nor is the point to argue that only one dynamic can be historically effective. In reality, any major political change will require interactions between each. Nor is the message that one is always more positive under a progressive view or the other necessarily negative. These are dynamics for radical social change of any normative orientation. So real-world diversities and complexities give many examples where either process spans the political spectrum. What is argued instead, are the following three - simple but potentially crucial - points. 
First, it is practically useful to distinguish these two processes. Exclusion of this distinction, or failures to make it in particular settings (with whatever words), will likely lead to a default situation in which vulnerabilities are reinforced to the modernistic fixation with control discussed in this chapter. On the basis of evidence documented here, this powerful current hegemony can reasonably be expected to respond to Sustainability pressures by emphasising expedient technical mechanisms of transition and sidelining the inconvenient (more care-focused) politics of transformation. Even without any countering bias, simply making the distinction is a precondition for rebalancing this political pressure. Second, there is the point made in this section, that it is the caring politics of transformation (rather than the more controlling management of transition), that has proven more crucially formative in the histories of emancipatory movements that have always driven Sustainability. This remains so, despite mixes of both processes being salient in different stages of complex real-world histories (and each dynamic being potentially regressive as well progressive). This history is important, in reminding how the unruly generative vibrancy of care presents a direct challenge to more controlling environmental authoritarianism currently consolidating around initiatives like 'the Anthropocene', 'the nexus', as well as manipulative 'nudge' strategies and 'planetary management'. Under these incumbent pressures, 'transition' processes thus tend to look after themselves. Serious progressive actions towards Sustainability should therefore emphasise complementary processes of 'transformation'. Third, there is the point that process matters. Although either political dynamic can lead to different normative ends, they are not simply 'plug and play'. Just as means are not entirely divorced from ends, so the contrasting attributes of each kind of process may be expected to leave sticky imprints on the consequences towards which they lead. No matter how well-intended they may be as means to challenge particular forms of control, interventions that are also controlling in different ways will likely reinforce this shared hegemony. Perhaps details will be reoriented. But underlying cultures of control remain intact. An extreme case is especially pertinent to historical efforts towards 'revolutionary' visions of transformative change. This is how organised revolutionary violence so often merely perpetuates (in new modes) the oppressive relations it was ostensibly intended to control. This is why Brundtland emphasised the caring imperatives of participatory (truly democratic) process.

If transformations to Sustainability really are taken seriously in the forms described here, then ambitiously radical reconfigurations of social relations from control towards care must not only feature in their aims, but in the dynamics through which these are enacted. So, for instance, knowledge and action need not be treated as separate and sequential as prescribed in the rigid controlling protocols of 'evidence-based policy' discussed earlier. Instead, they can be recognised to 
be deeply-entangled and mutually shaping - into multiple kinds of 'knowing doings' of kinds that shaped the culturing of Sustainability movements themselves (Stirling 2014a; 2014b).

As in exquisite changes of direction seen in flocking behaviours in nature, real social transformation is arguably only truly achieved through dynamics of diversity, creativity and democratic struggle equally in knowledge and action. Interestingly, the colloquial English word for such processes murmurations - refers both to the sense of unstructured mutual co-ordination and subaltern critical dissent (Stirling 2016). Choreographed in this way by autonomous normative compasses more than instrumentally coercive grids, this kind of politics of transformation defies not only any prior controlling orchestration, but also the imposition of expedient storylines after the fact. Formative phenomena are not neatly nested, but rhizomically entangled across all 'phases', 'scales' and 'levels'. Key generative processes eschew the conveniently tractable logistic curves so beloved of expert diagrams, instead surging to and fro in non-monotonic waves, where it may be unclear throughout, exactly which is the direction of change.

And if all this seems quite abstract and conceptual, it is not hard to see the practical salience of these contrasting faces of transformation for current high-stakes Sustainability politics. Consider, for example, the radically contrasting orientations of early moves (in alternative potential forms of Sustainability 'transitions' or 'transformations') currently underway in different sectors around the world. Entirely plausibly imaginable worldwide transformations to low-input care-intensive agroecology may be sidelined by transitions to high-technology synthetic biology driven intensive industrial agriculture. Transformations towards distributed community-based renewable energy and interactive energy services will be suppressed by transitions highlighting centralised grids for 'small modular' nuclear power reactors, interlinked with military propulsion and weapons infrastructures. Climate disruption may be alleviated by transformative improvements in political economy, resource efficiency and lifestyle change, or by transitions to global climate management using geoengineering technologies and their asssociated institutions of planetary control.

Each of these radically contrasting possibilities - and many more - are currently loudly propounded under different political views as (sometimes the 'only') possible means to find Sustainable resolutions to particular challenges in different sectors. In terms of their material feasibility, each is equally plausibly realisable in an appropriate economic context. But commitments in one direction foreclose chances of realising the other. Many well-known processes of lock-in that help shape single track 'race-like' modernistic visions for technology, infrastructure and institutional change As time goes on, path-dependencies increasingly do their job and entirely feasible alternative possibilities find themselves crowded out. Although these examples are stylised and diverse permutations are possible in this picture, the stakes between transition and transformation are clearly very high. 


\section{Conclusions and Practical Implications}

In order to draw practical conclusions, the key themes of this analysis are readily summarised. For all its progressive aspects, Modernity continues to be characterised by a range of fixations, fallacies and failures of control. Despite particular gains under variously-framed notions of social progress, these syndromes impact unacceptably on prevailing levels of inequality, injustice and environmental degradation. Against this backdrop, Sustainability can be seen to be about caring for these neglected harms to people, societies, nature - and their implications for the future of the world. This compels that radical improvements must be sustained in human wellbeing, social equity and ecological integrity - and that major political transformations must be enabled to achieve this.

A crucial challenge here is that, if it is constituted by relations of control rather than care, then Sustainability risks betraying both its foundations and its potential. Yet strong pressures exist to subvert Sustainability in just this fashion - to reinstate the modernist hegemonies of control that are so expedient to different kinds of incumbency around the world. For arguably more than any other factor, it is imaginations of control that maintain prevailing structures of privilege. And it is by such means that diverse power gradients in different sectors work to defend existing patterns of political, economic and cultural advantage. Aspects of this dynamic abound in global Sustainability governance, around: 'the nexus', 'grand challenges', 'nudge policies', 'planetary boundaries', 'environmental authoritarianism' and 'the Anthropocene'. Of course, to see this implies no lack of good faith on the part of individuals. Resurgence of control imaginations is not enacted by personal agency, but by emergent collective social dynamics. Indeed, this compounds the intractability. In order to defend the authentically formative caring imaginations of Sustainability against these aspiringly controlling pressures, key prescriptions flowing from this analysis are also quite readily expressed (See Box A). Some of the implications of these are discussed in more detail elsewhere (Stirling 2016). But what this leads to in particular, is a working distinction between relatively controlling forms of orderly hierarchically managed 'sustainable transition' and generally more caring kinds of unruly horizontally-co-ordinated 'transformations to Sustainability'. Many further specific practical implications of this contrast also arise (Stirling 2014b). Indeed, simply to propose the distinction can itself (in particular settings) sometimes be a potentially catalytic kind of action. Although taking contrasting forms in different contexts, it is arguably the dynamics of transformation (more than transition in these senses), that are most in keeping with the original driving values and practices of the collective action movements that brought the Brundtland Report into being. And it is associated qualities described here as care for (rather than control of) fellow people and the Earth, that feature most strongly in frameworks like the SDGs. These kinds of social change are not best 
enacted through rigidly categorical hierarchies of deterministic cause and effect. They do not depend on incumbent interests commissioning justificatory 'evidence' or 'research' from elite institutions of academic or policy actions. They thrive instead in mutually shaping relational 'knowing doings', that flow together in 'murmurations' in order to culture (not control) transformative social change.

The aim here is not the complete elimination of controlling Modernity. Indeed, such controlling ambitions would be ironically self-refuting. The vision is instead of a more nuanced balancing of care and control, reflexively deliberately countering the inherent biases of the modernistic cultures. Here, there is a threefold collective potential for murmurating moves (as summarised in Box A). First, they can broaden out apprehensions of different values, understandings and possibilities that constitute the emancipatory core of Sustainability. Second, they can open up appreciations for the multiplicity of alternative pathways that exist around the world for realising - iteratively and carefully - concrete moves towards Sustainability in particular settings. Third, they can aid moves away from Modernity in the vital process of letting go - subverting, dissolving and pivoting hegemonies of control, without their own negating dominations.

If global societies are serious about enabling people to care better for each other and for the Earth, then such actions may help in murmurating away from the fixations, fallacies and failures of controlling Modernity - in transformative struggles for the more caring possibilities of Sustainability. 


\section{Box A: Practical Implications for Action and Research}

One kind of action is directly to disrupt in different ways (as this chapter tries to do) the multi-faceted imaginations of control that sustain Modernity and resist more caring Sustainabilities. Such strategies include questioning what 'control' might be held to connote in any context. And this applies whether the 'control' in question comes in any of the diversity of guises mentioned here. For instance, moves can be made to correct exclusive preoccupations in mainstream politics with technological means rather than also social ends.

Conventional regulation in specific sectors based disproportionately on appraisals of single technological or policy means, can be pressured to compare alternative options. Insistence by high level institutions that 'the evidence' and 'sound science' are sufficient to determine action, can be refuted by demonstrating how all knowledge is openly uncertain - and shaped by (indeed, itself a form of) action. Transparent, accountable (openly political) attention to values is a matter of rigour. Performance of knowledge as singular and independent of society can be challenged by showing how key 'facts' depend on how they are viewed. This helps give space for appreciating the validity of a plurality of social understandings around any given issue. Such moves can help rebalance attention away from controlling notions of 'planetary management', towards more caring imaginations of Sustainability. It is also possible to disrupt and replace a host of more specific mechanisms that enforce these imaginations. Confident assertions by incumbents of their own elite 'real world' can be balanced by pointing out the persistent inconvenient intractabilities of the 'real real worlds' of nature, societies and people's lives. Targetable in this way are pressures to adopt: circumscribed accounts of 'risk'; artificial denials of complexity; untenable standardisations of diversity; impractical integrations of variabilities; iniquitous aggregations of social plurality; unjust legal externalisations of uncertainties and rhetorics presumptuously appropriating what counts as 'the way forward'.

Discussed elsewhere (Stirling 2016) and extending well away from formal governance arenas, a host of further 'knowing doings' mix action and knowledge together. Specific examples include 'political judo' or 'Trojan horse' strategies or moves well pioneered in collective action like 'civilizing hypocrisies', 'batting edge balls', 'bursting balloons', 'flipping predicates' or 'playing balls not players'. Mutuallychoreographing, these can grow in flocking 'murmurations' to enact more caring 'culturings' of transformations. 


\section{References}

Atkinson, G. et al. eds., 2014. Handbook of sustainable development, Cheltenham: Edward Elgar. Available at: http://eprints.Ise.ac.uk/2927/.

Barry, J., 2012. The Politics of Actually Existing Unsustainability: Human Flourishing in a Climate-Changed, Carbon-Constrained World, New York: Oxford University Press.

Baulcombe, D. et al., 2009. Reaping the benefits: science and the sustainable intensification of global agriculture, London: Royal Society.

Bellacasa, M.P. de la, 2017. Matters of Care: speculative ethics in more than human worlds, Minneapolis: Univ Minnesota Press.

Benner, P., 2000. The Quest for Control and the Possibilities of Care Heidegger, Coping, and Cognitive Science - essays in honor of Hubert L. Dreyfus. In M. Wrathall \& J. Malpas, eds. Cambridge MA: MIT Press.

Brundtland, G.H., 1987. Report of the World Commission on Environment and Development: Our Common Future, Oxford: Oxford Univ Press.

Doherty, B. \& Geus, M. De eds., 1996. Democracy and Green Political Thought: sustainability, rights and citizenship, London: Routledge.

Economist, 2015. The 169 commandments: the proposed sustainable development goals would be worse than useless. Economist, 1, pp.2015-2016.

Ellul, J., 1989. Technique,

Euractive, 2010. "Guilt card" to force green behaviour on consumers? Euractive, pp.1-2.

Fisher, B. \& Tronto, J., 1991. Toward a feminist theory of care. In E. Able \& M. Nelson, eds. Circles of Care: Work and Identity in Women's Lives. Albany, NY: SUNY Press.

Garud, R. \& Karnøe, P., 2003. Bricolage versus breakthrough: distributed and embedded agency in technology entrepreneurship. Research Policy, 32(2), pp.277-300. Available at: http://www.sciencedirect.com/science/article/pii/S0048733302001002.

Gilligan, C., 1993. In a Different Voice: psychological theory and women's development, Haan, J. de \& Sierman, C.L.J., 1996. New Evidence on the Relationship between Deomocracy and Economic Growth. Public Voice, 86(1/2), pp.175-198.

Held, V., 2005. The Ethics of Care: personal, political and global, Oxford: Oxford University Press. Available at: 
http://www.oxfordscholarship.com/view/10.1093/0195180992.001.0001/acprof9780195180992.

Hickman, L., 2010. James Lovelock: Humans are too stupid to prevent climate change. Guardian, (29 March), pp.2-5.

Leach, M., Scoones, I. \& Stirling, A., 2010. Dynamic Sustainabilities: technology, environment, social justice, London: Routledge.

Lovelock, J., 2006. The Revenge of Gaia, London: Penguin Books.

Mclaren, D.P., 2018. In a broken world: Towards an ethics of repair in the Anthropocene. The Anthropocene Review.

Norton, B.G., 2003. Searching for Sustainability: Interdisciplinary Essays in the Philosophy of Conservation Biology, Cambridge: Cambridge University Press.

Plumwood, V., 1993. Feminism and the Mastery of Nature, London: Routledge.

Pope_Francis, 2015. Laudato Si - Praised Be: encyclical on Care of Our Common Home, Rome: The Vatican.

Redclift, M., 1987. Sustainable Development: exploring the contradictions, London: Routledge.

Redclift, M. \& Springett, D., 2015. The Routledge International Handbook of Sustainable Development M. Redclift \& D. Springett, eds., Abingdon: Routledge.

Revkin, A.C., 2014. Exploring Academia's Role in Charting Paths to a 'Good' Anthropocene. New York Times, pp.1-7.

Robinson, F., 2011. The Ethics of Care: a feminist approach to human security, Philadelphia: Temple university Press.

Science, G.O. for, 2014. Annual Report of the Government Chief Scientific Adviser 2014 Innovation: managing risk, not avoiding it - report overview,

Shearman, D., Wayne Smith, J. \& Smith, J.W., 2007. The Climate Change Challenge and the Failure of Democracy, Westport CT: Praeger.

Smith, A., Fressoli, M. \& Thomas, H., 2013. Grassroots innovation movements: challenges and contributions. Journal of Cleaner Production, pp.1-11. Available at: http://linkinghub.elsevier.com/retrieve/pii/S0959652612006786 [Accessed November 14, 2013].

Stirling, A., 2015. Developing 'Nexus Capabilities': towards transdisciplinary methodologies, Brighton: SPRU, University of Sussex. 
Stirling, A., 2014a. From Sustainability to Transformation: dynamics and diversity in reflexive governance of vulnerability. In Vulnerability in Technological Cultures: new directions in research and governance. Cambridge, MA: MIT Press, pp. 1-61.

Stirling, A., 2016. Knowing Doing Governing: Realizing Heterodyne Democracies. In J.-P. Voß \& R. Freeman, eds. Knowing Governance: The Epistemic Construction of Political Order. Basingstoke: Palgrave Macmillan.

Stirling, A., 2011. Pluralising progress: From integrative transitions to transformative diversity. Environmental Innovation and Societal Transitions, 1(1).

Stirling, A., 2006. Precaution, Foresight and Sustainability: reflection and reflexivity in the governance of science and technology. In J.-P. Voss \& R. Kemp, eds. Reflexive Governance for Sustainable Development. Cheltenham: Edward Elgar, pp. 225-272.

Stirling, A., 2014b. Transforming power: Social science and the politics of energy choices. Energy Research \& Social Science, 1, pp.83-95. Available at: http://dx.doi.org/10.1016/j.erss.2014.02.001.

UN, 2015. Transforming Our World: the 2030 Agenda for Sustainable Development, New York: United Nations. 